\title{
Mechanism of higher incidence of ischemic mitral regurgitation in patients with inferior myocardial infarction: Quantitative analysis of left ventricular and mitral valve geometry in 103 patients with prior myocardial infarction
}

Toshiro Kumanohoso, MD

Yutaka Otsuji MD

Shiro Yoshifuku, MD

Keiko Matsukida, MD ${ }^{\mathrm{a}}$

Chihaya Koriyama, $\mathrm{MD}^{\mathrm{b}}$

Akira Kisanuki, MD

Shinichi Minagoe, $M D^{a}$

Robert A. Levine, $\mathrm{MD}^{\mathrm{C}}$

Chuwa Tei, MDa

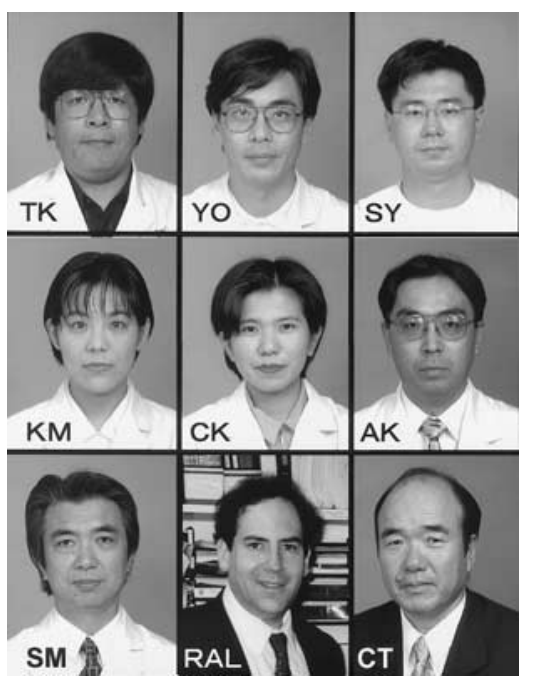

Dr Kumanohoso and colleagues

From the First Department of Internal Medicine, ${ }^{\text {a }}$ Department of Public Health, ${ }^{\mathrm{b}}$ Kagoshima University School of Medicine, Kagoshima, Japan, and the Cardiac Ultrasound Laboratory, ${ }^{\mathrm{c}}$ Massachusetts General Hospital, Boston, Mass.

Received for publication Feb 7, 2001; accepted for publication July 17, 2002.

Address for reprints: Yutaka Otsuji, MD, First Department of Internal Medicine, Kagoshima University School of Medicine, 8-35-1 Sakuragaoka, Kagoshima City, 890-8520, Japan (E-mail: yutakam.kufm. kagoshima-u.ac.jp).

J Thorac Cardiovasc Surg 2003;125:135-43

Copyright (C) 2003 by The American Association for Thoracic Surgery

0022-5223/2003\$30.00+0

doi: $10.1067 / \mathrm{mtc} .2003 .78$
Objective: The mechanism of higher incidence of ischemic mitral regurgitation in patients with inferior compared with anterior myocardial infarction despite less global left ventricular remodeling and dysfunction is controversial. We hypothesized that inferior myocardial infarction causes left ventricular remodeling, which displaces posterior papillary muscle away from its normal position, leading to ischemic mitral regurgitation.

Methods: In 103 patients with prior myocardial infarction (61 anterior and 42 inferior) and 20 normal control subjects, we evaluated the grade of ischemic mitral regurgitation on the basis of the percentage of Doppler jet area, left ventricular end-diastolic and end-systolic volumes, midsystolic mitral annular area, and midsystolic leaflet-tethering distance between papillary muscle tips and the contralateral anterior mitral annulus, which were determined by means of quantitative echocardiography.

Results: Global left ventricular dilatation and dysfunction were significantly less pronounced in patients with inferior myocardial infarction (left ventricular endsystolic volume: $52 \pm 18$ vs $60 \pm 24 \mathrm{~mL}$, inferior vs anterior infarction, $P<.05$; left ventricular ejection fraction: $51 \% \pm 9 \%$ vs $42 \% \pm 7 \%, P<.0001)$. However, the percentage of mitral regurgitation jet area and the incidence of significant regurgitation (percentage of jet area of $10 \%$ or greater) was greater in inferior infarction (percentage of jet area: $10.1 \% \pm 7.5 \%$ vs $4.4 \% \pm 7.0 \%, P=.0002$; incidence: $16 / 42$ $(38 \%)$ vs $6 / 61(10 \%), P<.0001$ ). The mitral annulus (area $=8.2 \pm 1.2 \mathrm{~cm}^{2}$ in control subjects) was similarly dilated in both inferior and anterior myocardial infarction $(9.7 \pm$ 1.7 vs. $9.5 \pm 2.3 \mathrm{~cm}^{2}$, no significant difference), and the anterior papillary muscletethering distance $(33.8 \pm 2.6 \mathrm{~mm}$ in control subjects) was also similarly and mildly increased in both groups $(35.2 \pm 2.4$ vs $35.2 \pm 2.8 \mathrm{~mm}$, no significant difference). However, the posterior papillary muscle-tethering distance $(33.3 \pm 2.3 \mathrm{~mm}$ in control subjects) was significantly greater in inferior compared with anterior myocardial infarction ( $38.3 \pm 4.1$ vs $34.7 \pm 2.9 \mathrm{~mm}, P=.0001)$. Multiple stepwise regression analysis identified the increase in posterior papillary muscle-tethering distance divided by body surface area as an independent contributing factor to the percentage of mitral regurgitation jet area $\left(r^{2}=0.70, P<.0001\right)$.

Conclusions: It is suggested that the higher incidence and greater severity of ischemic mitral regurgitation in patients with inferior compared with anterior myocardial infarction 
can be related to more severe geometric changes in the mitral valve apparatus with greater displacement of posterior papillary muscle caused by localized inferior basal left ventricular remodeling, which results in therapeutic implications for potential benefit of procedures, such as infarct plication and leaflet or chordal elongation, to reduce leaflet tethering.

$\int{ }^{\mathrm{s}}$

schemic mitral regurgitation (MR) is a vexing complication that adversely affects patients' prognoses. ${ }^{1-8}$ However, many clinical questions regarding ischemic MR are still controversial. ${ }^{1-6,9}$ One such question is the mechanism for a higher incidence of ischemic MR in patients with inferior myocardial infarction (MI) compared with those having anterior MI.,10 This higher incidence has been explained by posterior papillary muscle (PM) dysfunction in the right coronary artery territory. ${ }^{1,2}$ However, PM dysfunction per se fails to cause ischemic MR. ${ }^{11-13}$ Alternatively, left ventricular (LV) remodeling, dilatation, and dysfunction leading to geometric changes in the mitral apparatus, including PM displacement and annular dilatation, have been proposed to cause ischemic MR (Figure 1). ${ }^{13-24}$ However, patients with inferior MI typically present with less global LV remodeling and dysfunction, ${ }^{25}$ despite their higher incidence of ischemic MR.

Left anterior descending artery occlusion causes extensive ischemia, mainly in the anteroseptal and apical region, with minor direct involvement of the posteriorly positioned mitral valve apparatus. ${ }^{26}$ In contrast, right coronary artery occlusion causes less extensive LV ischemia but with direct involvement of important components of the mitral apparatus, including the basal inferior LV wall adjacent to the posterior PM and mitral annulus. Gorman and colleagues ${ }^{27}$ demonstrated experimentally that LV dilatation without prominent geometric changes in the mitral valve apparatus with anteroseptal MI does not cause ischemic MR, whereas posterior MI with mitral valve annular and posteromedial PM geometric changes causes MR in a sheep model. Thus it might also be expected that localized inferior basal LV remodeling in patients with inferior MI can potentially cause greater geometric changes in the mitral valve apparatus with displacement of posterior PM, despite lesser global LV remodeling and dysfunction than that seen in patients with anterior MI. Therefore the purpose of this study was to test the hypothesis that the higher incidence of ischemic MR in patients with inferior MI is associated with less global LV dilatation and dysfunction but with greater deformity of the mitral valve apparatus compared with that seen in patients with anteroseptal MI.

\section{Methods}

\section{Study Subjects}

Subjects consisted of 20 normal control subjects and 103 patients with prior MI, including a consecutive 61 patients with anteroseptal MI and a consecutive 42 patients with inferior MI. Inclusion criteria were, first, the presence of prior anteroseptal or inferior MI diagnosed on the basis of (1) a history of acute MI more than 1 month previously with serum creatine kinase levels above twice the upper normal value and (2) segmental LV wall motion abnormality of the anteroseptal or inferior wall. Second, these patients were referred for 2-dimensional and Doppler echocardiography between October 1997 and February 1999. Exclusion criteria were recent MI ( $\leq 1$ month), multiple MIs, previous heart surgery, MR caused by intrinsic mitral valvular lesions (including rheumatic changes, infective vegetations, and chordal or PM rupture), and other associated cardiac diseases, such as aortic valve or congenital heart disease. The normal control subjects had normal echocardiograms and no known cardiovascular disease.

Patient profiles are summarized in Table 1. Coronary angiography was done in 70 of 103 patients at our institution. Right or left coronary artery dominance was determined by which supplied the posterior diaphragmatic portion of the interventricular septum and the diaphragmatic surface of the LV.

\section{Echocardiographic Measurements}

Standard 2-dimensional and Doppler echocardiographic examinations with color flow mapping were done in all patients with 2.5-MHz transducers (commercially available ATL HDI 3000, Bothell, Wash; Toshiba SSH 380A, Tokyo, Japan; and Agilent Technologies, Sonos 5500, Andover, Mass). Special attention was paid to visualize the anterior and posterior PM tips in the apical 4and 2-chamber views. LV end-diastolic and end-systolic cavity areas were traced in those views, and LV volumes and ejection fractions (EFs) were obtained by using the modified biplane Simpson method. ${ }^{28}$ The LV wall was divided into 16 segments, and the number of segments with wall motion abnormality was estimated to evaluate the spatial extent of ischemic LV dysfunction. ${ }^{28} \mathrm{LV}$ shape or sphericity was assessed by using the LV short-axis/longaxis dimension ratio in the end-systolic apical 4-chamber view. ${ }^{29}$ Midsystolic mitral annular dimension was measured in the apical 4- and 2-chamber views, and its area was calculated by using an ellipsoid assumption (annular area $=\mathrm{d}_{1} \times \mathrm{d}_{2} \times \pi / 4$; Figure 2). ${ }^{30,31}$ The mitral annulus was identified as the leaflet hinge point. End-diastolic, end-systolic, and midsystolic frames were determined as the initial, last, and middle frame with systolic mitral leaflet closure. The mitral leaflet-tenting area between the leaflets and the line connecting the annular hinge points in the apical 4-chamber view was traced at midsystole to estimate the apical displacement of the mitral leaflets (Figure 2). ${ }^{14}$ The leaflet-tethering distance between the PM tips and the contralateral anterior mitral annulus was also measured in the apical 4- and 2-chamber views (Figure 2, $\ell_{1}$ and $\ell_{2}$ ) by using the anterior mitral annulus as a reference point to estimate PM displacement. ${ }^{21,32,33}$ The severity of MR was determined by the ratio of color Doppler jet area to left atrial area in midsystole. MR grade was estimated as trace, mild, 

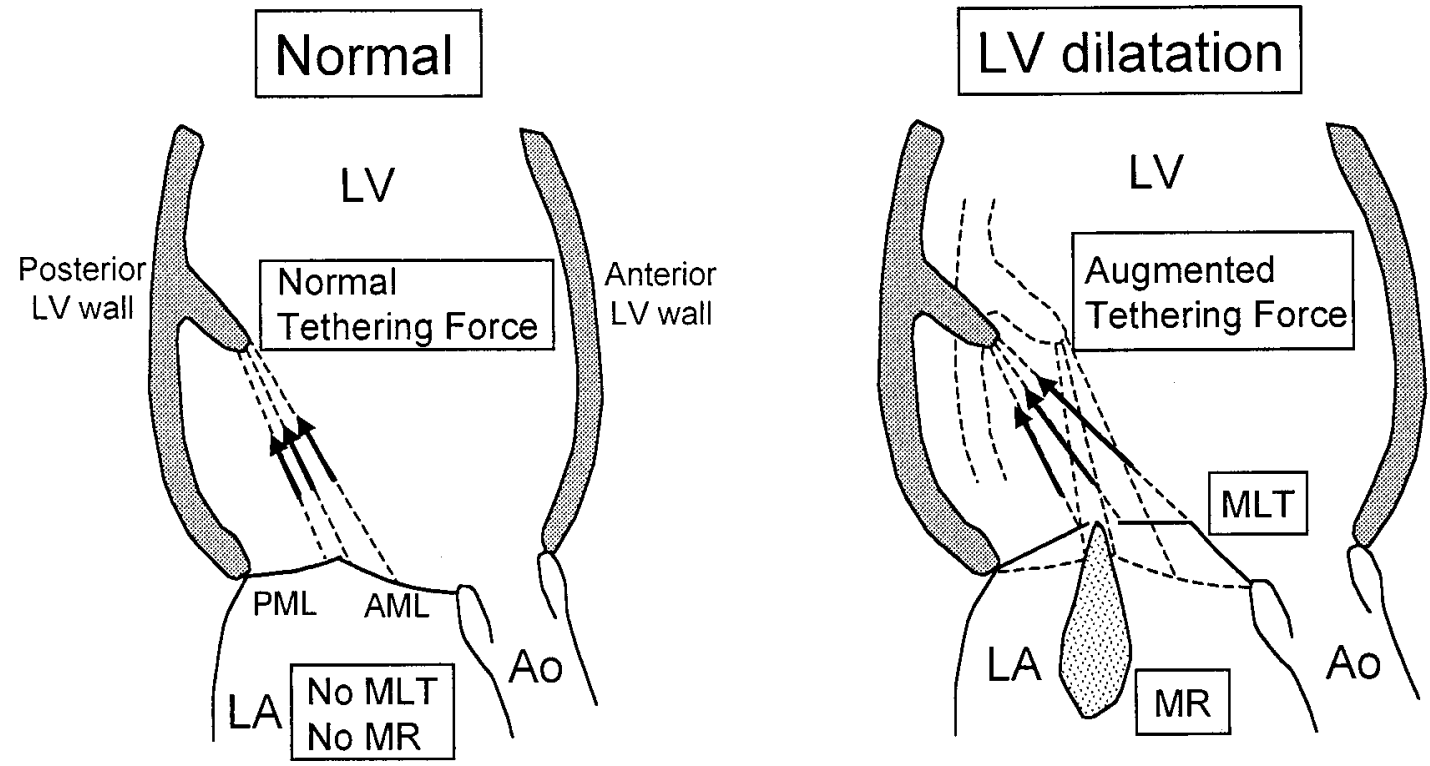

Figure 1. Leaflet-tethering hypothesis for the mechanism of mitral leaflet tenting and functional MR: left, normal leaflet tethering in a normal subject; right, augmented leaflet tethering resulting in apical displacement of the mitral leaflets and MR caused by LV dilation, systolic LV regional wall motion abnormalities, or both. MLT, Mitral leaflet tenting; $L A$, left atrium; $A o$, aorta; $A M L$, anterior mitral leaflet; $P M L$, posterior mitral leaflet.

TABLE 1. Patient profiles

\begin{tabular}{|c|c|c|c|c|c|}
\hline & $\begin{array}{l}\text { Control } \\
(\mathrm{n}=\mathbf{2 0})\end{array}$ & $\begin{array}{c}\text { Inferior MI } \\
(\mathrm{n}=42)\end{array}$ & vs & $\begin{array}{c}\text { Anterior MI } \\
(\mathrm{n}=61)\end{array}$ & $P$ value \\
\hline Age (y) & $50 \pm 18$ & $68 \pm 8$ & & $67 \pm 8$ & NS \\
\hline $\operatorname{Sex}(M / F)$ & $13 / 7$ & $35 / 7$ & & $48 / 13$ & NS \\
\hline Angina pectoris & $0 / 20$ & $2 / 42$ & & $5 / 61$ & NS \\
\hline Heart failure & $0 / 20$ & $4 / 42$ & & $7 / 61$ & NS \\
\hline \multicolumn{6}{|l|}{ Revascularization early after AMI } \\
\hline PTCA & $0 / 20$ & $35 / 42$ & & $48 / 61$ & NS \\
\hline PTCA + PTCR & $0 / 20$ & $0 / 42$ & & $2 / 61$ & NS \\
\hline PTCA + t-PA & $0 / 20$ & $0 / 42$ & & $1 / 61$ & NS \\
\hline Not performed & $\mathrm{N} / \mathrm{A}$ & $7 / 42$ & & $10 / 61$ & NS \\
\hline Number of LV segments with asynergy & $0 \pm 0$ & $1.9 \pm 0.7$ & & $6.5 \pm 0.6$ & $<.0001$ \\
\hline Coronary artery dominance (R/NR) & $\mathrm{N} / \mathrm{A}$ & $\begin{array}{l}26 / 4 \\
n=30\end{array}$ & & $\begin{array}{l}37 / 3 \\
n=40\end{array}$ & NS \\
\hline Time lapse after acute $\mathrm{MI}(\mathrm{mo})$ & $0 \pm 0$ & $29 \pm 38$ & & $26 \pm 29$ & NS \\
\hline
\end{tabular}

$A M I$, Acute myocardial infarction; PTCA, percutaneous transluminal coronary angioplasty; PTCR, percutaneous transluminal coronary reperfusion; $t-P A$, tissue plasminogen activator; $R$, right coronary artery dominance; $N R$, nonright coronary artery dominance. $P$ values are shown for comparison between anterior and inferior Ml.

moderate, or severe on the basis of ratios of greater than $0 \%$ to $10 \%$, greater than $10 \%$ to $20 \%$, greater than $20 \%$ to $40 \%$, and greater than $40 \%$, respectively. ${ }^{34,35}$

\section{Reproducibility of Measurements}

Two independent observers repeated measurements of mitral annular area and PM-tethering distance from 10 patients' single echocardiographic recordings. The differences in their measurements were used to express interobserver variability. The same observer repeated the measurements to estimate intraobserver variability.

\section{Statistical Analysis}

Results were expressed as means $\pm \mathrm{SD}$. Variables were compared between groups by using the unpaired Student $t$ test. Incidences in the 2 groups were compared by using the $\chi^{2}$ test. Determinants of the percentage of MR jet area and mitral leaflet-tenting area were explored by entering the end-diastolic and end-systolic LV vol- 
TABLE 2. Echocardiographic measurements

\begin{tabular}{|c|c|c|c|c|c|}
\hline & $\begin{array}{c}\text { Control } \\
(n=20)\end{array}$ & $\begin{array}{c}\text { Inferior MI } \\
(\mathrm{n}=42)\end{array}$ & vs & $\begin{array}{c}\text { Anterior MI } \\
(\mathrm{n}=61)\end{array}$ & $P$ value \\
\hline LVEDV (mL) & $87 \pm 14$ & $101 \pm 19$ & & $101 \pm 28$ & NS \\
\hline LVEDVI $\left(\mathrm{mL} / \mathrm{m}^{2}\right)$ & $53 \pm 8$ & $63 \pm 14$ & & $64 \pm 21$ & NS \\
\hline LVESV $(\mathrm{mL})$ & $35 \pm 8$ & $52 \pm 18$ & & $60 \pm 24$ & $<.05$ \\
\hline LVESVI $\left(\mathrm{mL} / \mathrm{m}^{2}\right)$ & $21 \pm 5$ & $33 \pm 12$ & & $38 \pm 17$ & $<.05$ \\
\hline LVEF (\%) & $60 \pm 5$ & $51 \pm 9$ & & $42 \pm 7$ & $<.001$ \\
\hline \multicolumn{6}{|l|}{ Incidence of MR } \\
\hline Trace/none & $20(100 \%)$ & $26(62 \%)$ & & $55(90 \%)$ & $<.0001$ \\
\hline Mild & $0(0 \%)$ & $10(24 \%)$ & & $4(7 \%)$ & $<.01$ \\
\hline Moderate & $0(0 \%)$ & $6(14 \%)$ & & $2(3 \%)$ & $<.01$ \\
\hline Severe & $0(0 \%)$ & $0(0 \%)$ & & $0(0 \%)$ & NS \\
\hline Incidence of MR in patients with non-RCA dominance & $\mathrm{N} / \mathrm{A}$ & $1 / 4$ & & $0 / 3$ & NS \\
\hline Mitral annular area $\left(\mathrm{cm}^{2}\right)$ & $8.2 \pm 1.2$ & $9.7 \pm 1.7$ & & $9.5 \pm 2.3$ & NS \\
\hline $\mathrm{LV}(\mathrm{D})(\mathrm{mm})$ & $34.8 \pm 2.5$ & $37.2 \pm 3.0$ & & $39.0 \pm 2.9$ & $<.01$ \\
\hline $\mathrm{LV}(\mathrm{L})(\mathrm{mm})$ & $63.1 \pm 4.4$ & $64.7 \pm 3.4$ & & $72.6 \pm 5.0$ & $<.01$ \\
\hline $\mathrm{D} / \mathrm{L}$ & $0.55 \pm 0.04$ & $0.58 \pm 0.03$ & & $0.54 \pm 0.02$ & $<.01$ \\
\hline
\end{tabular}

$\angle V E D V$, Left ventricular end-diastolic volume; $L V E S V$, left ventricular end-systolic volume; $L V E F$, left ventricular ejection fraction; MR, mitral regurgitation; $R C A$, right coronary artery; $D$, short-axis dimension; $L$, long-axis dimension (increasing $D / L$ ratio indicates greater sphericity). $P$ values are shown for comparison between anterior and inferior $\mathrm{Ml}$.

\section{Apical 4-chamber}

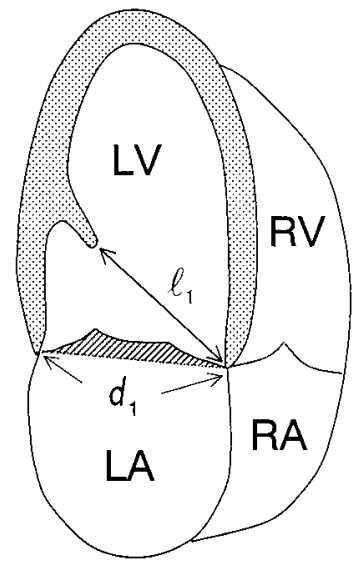

Apical 2-chamber

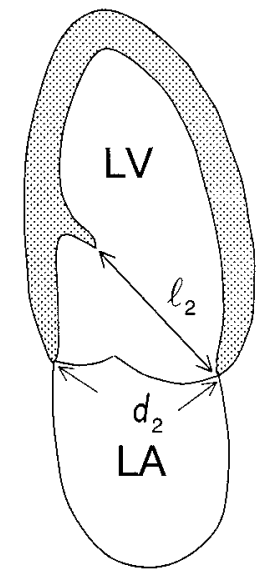

Figure 2. Methods to measure (1) the mitral annular area from 2 diameters in apical views, (2) the mitral leaflet-tenting area between the mitral leaflets and a line connecting mitral annular hinge points in the midsystolic apical 4-chamber view (dashed area shown in the left panel), and (3) leaflet-tethering lengths between anterior or posterior PM tips and contralateral anterior mitral annulus $\left(\ell_{1}\right.$ and $\left.\ell_{2}\right)$. $L V$, Left ventricle; $L A$, left atrium; $R V$, right ventricle; $R A$, right atrium.

umes, EF, LV sphericity, mitral annular area, PM leaflet-tethering distance, and these variables normalized by body surface area (BSA) into univariate and stepwise multiple regression analysis. Because distribution of the mitral leaflet-tenting area was skewed, the area was transformed by using the Box-Cox method with the following formula:

$$
\text { Transformed area }=\left[(\text { Area }+1)^{-1.5}-1\right] /(-1.5)^{36}
$$

\section{Results}

\section{Remodeling and Dysfunction in Anterior and Inferior MI}

Patients with both inferior and anterior MIs had significantly larger LV end-systolic volumes and lower EFs than normal subjects. The increase in LV end-systolic volume, reduction in EF, and number of segments with asynergy were significantly greater in patients with anterior compared with inferior MI (Tables 1 and 2).

\section{Mitral Leaflet Tenting and Ischemic MR}

Data on mitral leaflet tenting and ischemic MR are shown in Table 2 and Figure 3. The mitral leaflet-tenting area was significantly increased in patients with both anterior and inferior MI. Despite smaller changes in LV systolic volume and $\mathrm{EF}$, the increase in tenting area was significantly greater in patients with inferior compared with anterior MI $(P=$ .0003). The percentage of MR jet area was also significantly increased in both groups, with the increase again being significantly greater in patients with inferior MI $(P=$ .0002), which is consistent with their higher incidence of mild or greater MR $(P<.0001)$.

\section{Measures of the Mitral Valve Apparatus}

Data on measures of the mitral valve apparatus are shown in Table 2 and Figure 3. Patients with both inferior and anterior MIs had significant but comparable increases in mitral annular area and the anterior PM leaflet-tethering distance compared with that seen in control subjects $(P<.05$ vs control subjects; $P=$ not significant, inferior vs anterior). In contrast, posterior PM-tethering distance was significantly increased in patients with inferior compared with anterior MI. 

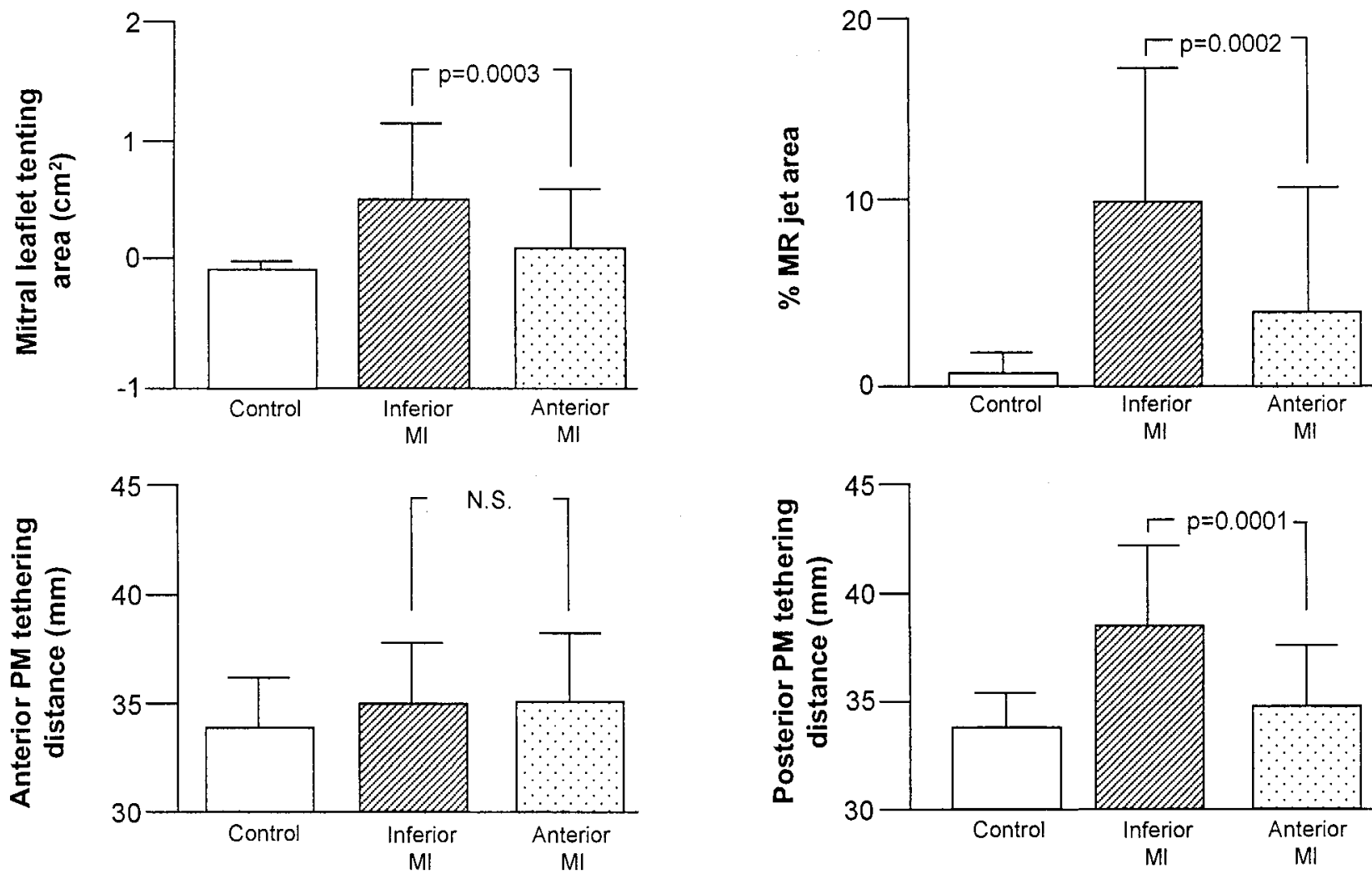

Figure 3. Bar graphs showing differences in mitral leaflet-tenting area, percentage of MR jet area, and anterior or posterior PM-tethering distances between patients with anterior and inferior infarction. NS, Not significant.

\section{Determinants of Mitral Leaflet-Tenting Area and Percentage of MR Jet Area}

Univariate predictors for the mitral leaflet-tenting area in the entire patient set were LV end-diastolic and end-systolic volume, mitral annular area, LV sphericity, the leaflettethering distance of both PMs, these variables normalized by BSA, and inferior MI location. Multiple stepwise regression analysis identified the increase in posterior PM leaflettethering distance normalized by BSA as an independent contributing factor to the mitral leaflet-tenting area, along with normalized mitral annular area and inferior MI location $\left(r^{2}=0.60\right.$, Table 3 and Figure 4).

Univariate predictors of the percentage of MR jet area in the entire patient set were LV end-diastolic and end-systolic volume, mitral annular area, LV sphericity, the leaflettethering distance of both PMs, these variables normalized by BSA, and inferior MI location. Multiple stepwise regression analysis similarly identified the increase in the posterior PM leaflet-tethering distance normalized by BSA as an independent contributing factor to the percentage of MR jet area, along with normalized LV end-diastolic volume, inferior MI location, and mitral annular area $\left(r^{2}=0.77\right.$, Table 4 and Figure 5).

\section{Reproducibility of Measurements}

Interobserver and intraobserver variability for the measurements of mitral annular area were $0.7 \pm 0.3$ and $0.4 \pm 0.1$ $\mathrm{cm}^{2}$ or $6.0 \% \pm 2.6 \%$ and $3.1 \% \pm 0.8 \%$ of the mean value, respectively. Interobserver and intraobserver variability for the measurements of PM leaflet-tethering distance were $1.3 \pm 0.5$ and $0.6 \pm 0.2 \mathrm{~mm}$ or $3.7 \% \pm 1.4 \%$ and $2.4 \% \pm$ $0.8 \%$ of the mean value, respectively.

\section{Discussion}

Mechanism of Higher Incidence of Ischemic MR With Inferior MI

This study demonstrated that MR and apical displacement of the mitral leaflets were more severe in patients with inferior than in patients with anterior MI, despite smaller changes in LV systolic volume and reduction in EF. Therefore the higher incidence of ischemic MR in patients with inferior MI cannot be explained by global LV dilatation and dysfunction. In contrast, localized deformity of the mitral valve complex was greater in patients with inferior MI; specifically, the tethering distance from the posterior PM, typically in the infarct zone, to the anterior annulus was significantly longer in patients with inferior MI. The ante- 


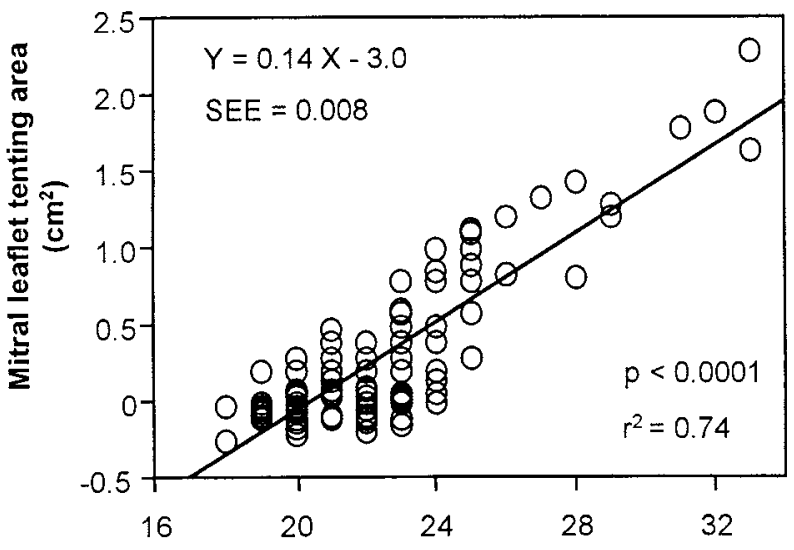

Posterior PM Tethering Distance / BSA $\left(\mathrm{mm} / \mathrm{m}^{2}\right)$

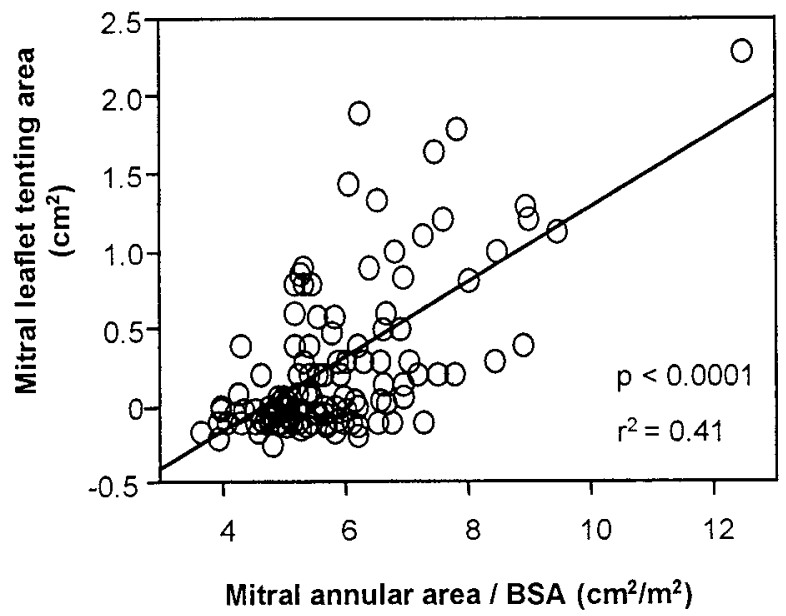

Mitral annular area / BSA $\left(\mathrm{cm}^{2} / \mathrm{m}^{2}\right)$

Figure 4. Scattergraphs showing relationships between mitral leaflet-tenting area and its determinants. Multiple stepwise regression analysis identified the increase in posterior PM-tethering distance/BSA as an independent contributing factor to the mitral leaflet-tenting area, along with mitral annular area/BSA and inferior MI location.

TABLE 3. Determinants of mitral leaflet-tenting area

\begin{tabular}{|c|c|c|c|c|}
\hline Univariate analysis & Coefficients & SE & $r^{2}$ & $P$ value \\
\hline LV EDV/BSA $\left(\mathrm{mL} / \mathrm{m}^{2}\right)$ & 0.005 & 0.001 & 0.18 & $<.001$ \\
\hline LV ESV/BSA $\left(\mathrm{mL} / \mathrm{m}^{2}\right)$ & 0.004 & 0.001 & 0.11 & $<.001$ \\
\hline $\operatorname{LV} \operatorname{EF}(\%)$ & $(-)$ & $(-)$ & $(-)$ & NS \\
\hline LV D/L & 2.0 & 0.63 & 0.09 & .002 \\
\hline Posterior PM tethering distance/BSA $\left(\mathrm{mm} / \mathrm{m}^{2}\right)$ & 0.05 & 0.005 & 0.56 & $<.001$ \\
\hline Anterior PM tethering distance/BSA $\left(\mathrm{mm} / \mathrm{m}^{2}\right)$ & 0.05 & 0.008 & 0.25 & $<.001$ \\
\hline Mitral annular area/BSA $\left(\mathrm{cm}^{2} / \mathrm{m}^{2}\right)$ & 0.09 & 0.013 & 0.32 & $<.001$ \\
\hline Inferior location of $\mathrm{MI}(0=$ anterior, $1=$ inferior $)$ & 0.18 & 0.04 & 0.17 & $<.001$ \\
\hline Multivariate analysis & Coefficients & SE & $t$ & $P$ value \\
\hline LV EDV/BSA $\left(\mathrm{mL} / \mathrm{m}^{2}\right)$ & $(-)$ & $(-)$ & $(-)$ & NS \\
\hline LV ESV/BSA $\left(\mathrm{mL} / \mathrm{m}^{2}\right)$ & $(-)$ & $(-)$ & $(-)$ & NS \\
\hline $\mathrm{LV} \mathrm{D} / \mathrm{L}$ & $(-)$ & $(-)$ & $(-)$ & NS \\
\hline Posterior PM tethering distance $/ \mathrm{BSA}\left(\mathrm{mm} / \mathrm{m}^{2}\right)$ & 0.037 & 0.007 & 5.6 & $<.001$ \\
\hline Anterior PM tethering distance $/ \mathrm{BSA}\left(\mathrm{mm} / \mathrm{m}^{2}\right)$ & $(-)$ & $(-)$ & $(-)$ & NS \\
\hline Mitral annular area/BSA $\left(\mathrm{cm}^{2} / \mathrm{m}^{2}\right)$ & 0.035 & 0.014 & 2.6 & .01 \\
\hline Inferior location of $\mathrm{MI}(0=$ anterior, $1=$ inferior $)$ & 0.09 & 0.03 & 3.0 & .004 \\
\hline
\end{tabular}

$\mathrm{F}$ value $(3,99)=50.4$. Interaction terms between variables were all not significant with $P$ values of greater than .05 . EDV, End-diastolic volume; ESV, end-systolic volume; $D / L$, LV short-axis to long-axis dimension ratio.

rior PM-tethering distance and mitral annular dilatation were comparable between the 2 groups. Multiple stepwise regression analysis identified the increase in posterior PMtethering distance as the independent determinant of mitral leaflet-tenting area and percentage MR jet area. Therefore, the results suggest that ischemic MR is not primarily related to global LV remodeling or dysfunction but rather to localized remodeling, causing deformity of the mitral valve complex, especially at the PM attachment in the inferior basal lesion.

\section{Relation to Previous Studies}

Our results are consistent with those of previous investigations demonstrating higher incidences of ischemic MR in patients with inferior compared with anterior MI., 70,37 The results also support the leaflet-tethering hypothesis for the mechanism of ischemic MR, which proposes that LV remodeling, leading to geometric changes in the mitral valve complex, causes ischemic MR. ${ }^{13-19,21,24,27,32,33,38}$ The importance in the mechanism of ischemic MR of localized basal posteroinferior LV remodeling in causing geometric 


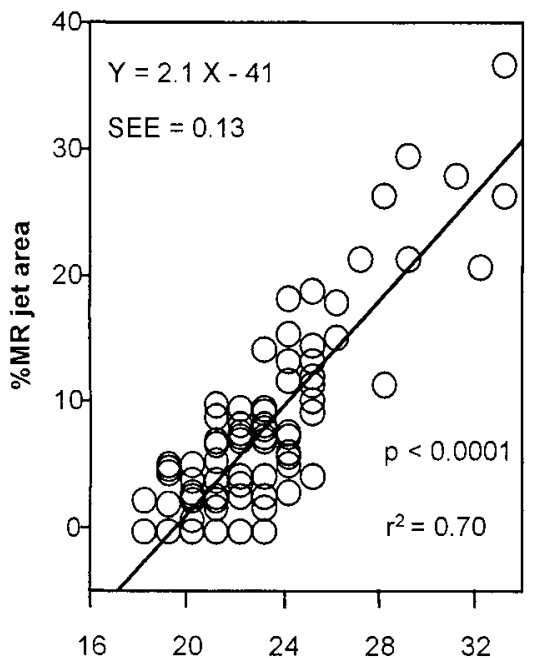

Posterior PM Tethering Distance / BSA $\left(\mathrm{mm} / \mathrm{m}^{2}\right)$

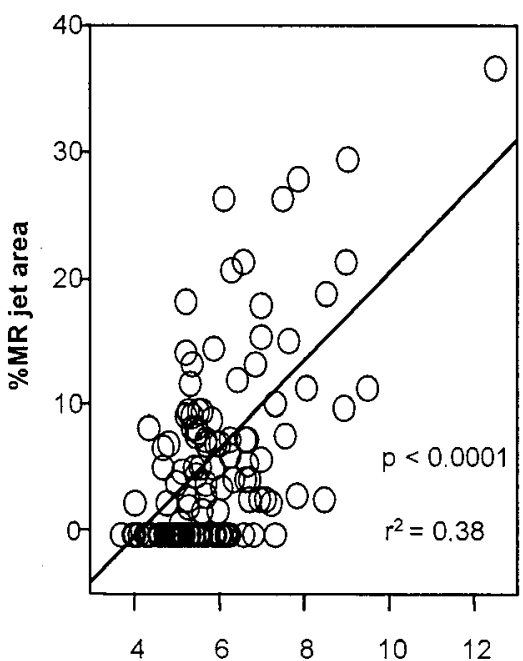

Mitral annular area / BSA $\left(\mathrm{cm}^{2} / \mathrm{m}^{2}\right)$

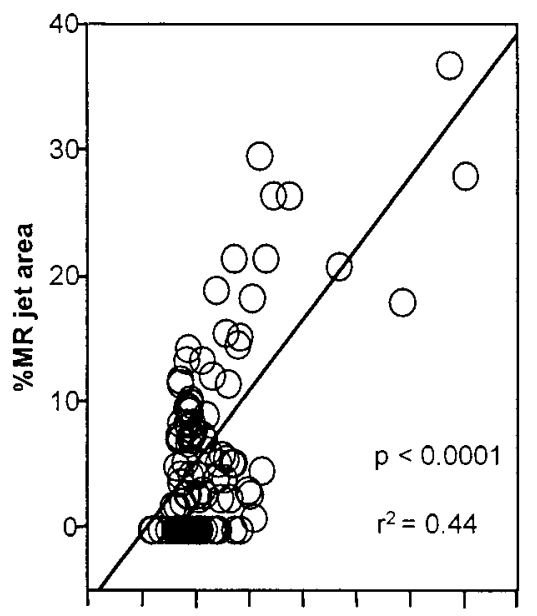

$20 \quad 40 \quad 60 \quad 80 \quad 100120140160180$

LV end-diastolic volume / BSA $\left(\mathrm{ml} / \mathrm{m}^{2}\right)$

Figure 5. Scattergraphs showing relationships between percentage of MR jet area and its determinants. Multiple stepwise regression analysis identified the increase in posterior PM-tethering distance/BSA as an independent contributing factor to the percentage of MR jet area, along with LV end-diastolic volume/BSA, inferior MI location, and mitral annular area.

TABLE 4. Determinants of percentage MR jet area

\begin{tabular}{|c|c|c|c|c|}
\hline Univariate analysis & Coefficients & SE & $r^{2}$ & $P$ value \\
\hline LV EDV/BSA (mL/m²) & 0.28 & 0.029 & 0.44 & $<.0001$ \\
\hline LV ESV/BSA $\left(\mathrm{mL} / \mathrm{m}^{2}\right)$ & 0.29 & 0.04 & 0.37 & $<.0001$ \\
\hline LV EF $(\%)$ & $(-)$ & $(-)$ & $(-)$ & NS \\
\hline $\mathrm{LV} \mathrm{D} / \mathrm{L}$ & 49 & 19 & 0.05 & .01 \\
\hline Posterior PM tethering distance/BSA $\left(\mathrm{mm} / \mathrm{m}^{2}\right)$ & 2.1 & 0.13 & 0.70 & $<.0001$ \\
\hline Anterior PM tethering distance/BSA $\left(\mathrm{mm} / \mathrm{m}^{2}\right)$ & 2.1 & 0.25 & 0.37 & $<.0001$ \\
\hline Mitral annular area/BSA $\left(\mathrm{cm}^{2} / \mathrm{m}^{2}\right)$ & 3.5 & 0.41 & 0.38 & $<.0001$ \\
\hline Inferior location of $\mathrm{MI}(0=$ anterior, $1=$ inferior $)$ & 5.7 & 1.44 & 0.13 & $<.001$ \\
\hline Multivariate analysis & Coefficients & SE & $t$ & $P$ value \\
\hline LV EDV/BSA (mL/m²) & 0.12 & 0.03 & 4.3 & $<.001$ \\
\hline LV ESV/BSA $\left(\mathrm{mL} / \mathrm{m}^{2}\right)$ & $(-)$ & $(-)$ & $(-)$ & NS \\
\hline LV D/L & $(-)$ & $(-)$ & $(-)$ & NS \\
\hline Posterior PM tethering distance/BSA $\left(\mathrm{mm} / \mathrm{m}^{2}\right)$ & 1.3 & 0.2 & 5.9 & $<.001$ \\
\hline Anterior PM tethering distance/BSA $\left(\mathrm{mm} / \mathrm{m}^{2}\right)$ & $(-)$ & $(-)$ & $(-)$ & NS \\
\hline Mitral annular area/BSA $\left(\mathrm{cm}^{2} / \mathrm{m}^{2}\right)$ & 0.82 & 0.38 & 2.2 & .03 \\
\hline Inferior location of $\mathrm{MI}(0=$ anterior, $1=$ inferior $)$ & 2.7 & 0.9 & 3.1 & .003 \\
\hline
\end{tabular}

F value $(4,98)=81.2$. Interaction terms between variables were all not significant, with $P$ values of greater than .05 . EDV, End-diastolic volume; ESV, end-systolic volume; $D / L$, LV short-axis to long-axis dimension ratio.

changes in the mitral valve complex, as opposed to global LV remodeling and dysfunction, have been demonstrated in a previous sheep experiment ${ }^{27}$ and confirmed in the present clinical study.

These results emphasize the importance of posterior PM displacement in the mechanism of ischemic MR in patients with inferior MI but do not indicate that anterior PM displacement is not important. Yiu and associates ${ }^{38}$ studied the mechanism of functional ischemic MR in patients with an LV EF of less than 50\%. They studied patients with global and segmental LV dysfunction and a mean $\mathrm{EF}$ of $31 \% \pm$ 9\% and demonstrated that both PM displacements are 
equally important in the mechanism of functional MR. ${ }^{37}$ Our data are generally consistent with their results in that they demonstrate the importance of PM displacement in the mechanism of ischemic MR. However, the contribution of posterior and anterior PM displacement was not equal in the present study. We studied the mechanism of MR only in patients with inferior or anterior segmental LV dysfunction and with a higher mean EF of $45 \% \pm 9 \%$. Experimental investigations demonstrated equal contributions from both PM displacements with global LV dysfunction and a predominant contribution from posterior PM displacement with inferoposterior segmental dysfunction. ${ }^{21,32,33}$ It has also been shown in animal experiments that segmental anteroseptal ischemia causes only modest deformity of the mitral apparatus. ${ }^{27,39}$ We can therefore suggest that differences in the patient population can potentially explain whether the posterior and anterior PM displacements make equal or unequal contributions to ischemic MR.

\section{Limitations}

Estimation of geometric change in the mitral apparatus was done by using a single 2-dimensional echocardiogram, and therefore we could not evaluate 3-dimensional PM displacement in multiple directions, as with 3-dimensional echocardiography. ${ }^{21,32,33}$ However, the tethering distance between the PM tip and the contralateral anterior mitral annulus determined by using 2-dimensional echocardiography can potentially offer an alternative measurement of leaflet tethering that has been shown to correlate well with the mitral leaflet-tenting area $\left(r^{2}=0.74\right)$ and with the percentage of MR jet area $\left(r^{2}=0.70\right) .33,38$

We investigated the mechanism for a higher incidence of ischemic MR in patients with inferior MI, but the grade of MR was evaluated semiquantitatively. Time since MR developed could not be estimated, and infarct mass was not quantified. In this series there were no patients with severe MR, who most require surgical intervention. Further investigations might address such issues prospectively.

\section{Clinical Implications}

These results emphasize the importance of segmental LV remodeling and dysfunction on mitral leaflet function and the differences in these effects depending on the involved segment. This effect can be a consideration in decisions regarding the potential benefit of revascularization in inferior infarctions. ${ }^{10}$ The findings also suggest that surgical techniques, in addition to annular size reduction, could potentially benefit patients by reversing geometric changes in the mitral valve complex. Such maneuvers might include coronary artery bypass grafting, especially to the right or left circumflex coronary artery territory with viable myocardium; infarct plication or posterior wall excision to reduce infarct bulging 32 ; or leaflet or chordal elongation.
Although mitral annuloplasty can usually eliminate ischemic MR, ${ }^{40,41}$ clinical observations demonstrate that MR might persist after ring implantation, which is consistent with leaflet tethering in addition to annular dilatation. ${ }^{42,43}$ Isolated insertion of an annuloplasty ring can limit annular area and improve coaptation but might not reduce leaflet tethering, resulting in persistent MR. ${ }^{44}$ Therefore understanding the deformation of the mitral valve complex is a prerequisite to successful correction of ischemic MR. ${ }^{27}$

We thank Drs Hachiro Obata and Fumio Nakano for their dedicated review of the coronary angiograms.

\section{References}

1. Burch GE, De Pasquale NP, Phillips JH. Clinical manifestations of papillary muscle dysfunction. Arch Intern Med. 1963;112:112-7.

2. Phillips JH, Burch GE, De Pasquale NP. The syndrome of papillary muscle dysfunction: its clinical recognition. Ann Intern Med. 1963; 59:508-20.

3. Rankin JS, Hickey MSJ, Smith LR, et al. Ischemic mitral regurgitation. Circulation. 1989;79(suppl I):116-21.

4. Lehmann KG, Francis CK, Dodge HT and the TIMI Study Group. Mitral regurgitation in early myocardial infarction: incidence, clinical detection, and prognostic implications. Ann Intern Med. 1992;117: 10-7.

5. Lamas GA, Mitchell GF, Flaker GC, et al. Clinical significance of mitral regurgitation after acute myocardial infarction. Circulation. 1997;96:827-33.

6. Kisanuki A, Otsuji Y, Kuroiwa R, et al. Two-dimensional echocardiographic assessment of papillary muscle contractility in patients with prior myocardial infarction. J Am Coll Cardiol. 1993;21:932-8.

7. Izumi S, Miyatake K, Beppu S, et al. Mechanism of mitral regurgitation in patients with myocardial infarction: a study using real-time two-dimensional Doppler flow imaging and echocardiography. Circulation. 1987;76:777-85.

8. Grigioni F, Enriquez-Sarano M, Zehr KJ, Bailey KR, Tajik AJ. Ischemic mitral regurgitation: long-term outcome and prognostic implications with quantitative Doppler assessment. Circulation. 2001;103: 1759-64.

9. Heikkila J. Mitral incompetence complicating acute myocardial infarction. Br Heart J. 1967;29:162-9.

10. Leor J, Feinberg MS, Vered Z, et al. Effect of thrombolytic therapy on the evolution of significant mitral regurgitation in patients with a first inferior myocardial infarction. J Am Coll Cardiol. 1993;21:1661-6.

11. Miller GE Jr, Cohn KE, Kerth WJ, Selzer A, Gerbode F. Experimental papillary muscle infarction. J Thorac Cardiovsc Surg. 1968;56:611-6.

12. Mittal AK, Langston M Jr, Cohn KE, Selzer A, Kerth WJ. Combined papillary muscle and left ventricular wall dysfunction as a cause of mitral regurgitation: an experimental study. Circulation. 1971;44:17480 .

13. Kaul S, Spotnitz WD, Glasheen WP, Touchstone DA. Mechanism of ischemic mitral regurgitation: an experimental evaluation. Circulation. 1991;84:2167-80.

14. Godley RW, Wann LS, Rogers EW, Feigenbaum H, Weyman AE. Incomplete mitral leaflet closure in patients with papillary muscle dysfunction. Circulation. 1981;63:565-71.

15. Kono T, Sabbah HN, Rosman H, et al. Mechanism of functional mitral regurgitation during acute myocardial ischemia. J Am Coll Cardiol. 1992;19:1101-5.

16. Kono T, Sabbah HN, Stein PD, Brymer JF, Khaja F. Left ventricular shape as a determinant of functional mitral regurgitation in patients with severe heart failure secondary to either coronary artery disease or idiopathic dilated cardiomyopathy. Am J Cardiol. 1991;68:355-9.

17. Sabbah HN, Kono T, Rosman H, Jafri S, Stein PD, Goldstein S. Left ventricular shape: a factor in the etiology of functional mitral regurgitation in heart failure. Am Heart J. 1992;123:961-6. 
18. Kono T, Sabbah HN, Rosman H, Alam M, Jafri S, Goldstein S. Left ventricular shape is the primary determinant of functional mitral regurgitation in heart failure. J Am Coll Cardiol. 1992;20:1594-8.

19. Sabbah HN, Kono T, Stein PD, Mancini GBJ, Goldstein S. Left ventricular shape changes during the course of evolving heart failure. Am J Physiol. 1992;263:H266-70.

20. Dent JM, Spotnitz WD, Nolan SP, Jayaweera AR, Glasheen WP, Kaul S. Mechanism of mitral leaflet excursion. Am J Physiol. 1995;269: H2100-8.

21. Otsuji Y, Handschumacher MD, Schwammenthal E, et al. Insights from three-dimensional echocardiography into the mechanism of functional mitral regurgitation: direct in vivo demonstration of altered leaflet tethering geometry. Circulation. 1997;96:1999-2008.

22. Boltwood CM, Tei C, Wong M, Shah PM. Quantitative echocardiography of the mitral complex in dilated cardiomyopathy: the mechanism of functional mitral regurgitation. Circulation. 1983;68:498-508.

23. Komeda M, Glasson JR, Bolger AF, et al. Geometric determinants of ischemic mitral regurgitation. Circulation. 1997;96(suppl II): II12833.

24. Matsuzaki M, Yonezawa F, Toma Y, et al. Experimental mitral regurgitation in Ischemia-induced papillary muscle dysfunction. J Cardiol. 1988;18(Suppl 18):121-6.

25. Roberts R, Morris D, Pratt CM, Alexander RW. Pathophysiology, recognition, and treatment of acute myocardial infarction and its complications. In: Schlant RC, Alexander RW, editors. The heart: arteries and veins. New York: McGraw-Hill Inc; 1994. p. 1137.

26. Segar DS, Brown SE, Sawada SG, Ryan T, Feigenbaum H. Dobutamine stress echocardiography: correlation with coronary lesion severity as determined by quantitive angiography. J Am Coll Cardiol. 1992;19:1197-202.

27. Gorman JH, Gorman RC, Plappert T, et al. Infarct size and location determine development of mitral regurgitation in the sheep model. J Thorac Cardiovasc Surg. 1988;115:615-22.

28. Schiller NB, Shah PM, Crawford M, et al. Recommendations for quantification of the left ventricle by two-dimensional echocardiography. J Am Soc Echocardiogr. 1989;2:358-67.

29. D’Cruz IA, Shroff SG, Janicki JS, Jain A, Reddy HK, Lakier JB. Differences in the shape of the normal, cardiomyopathic, and volume overloaded human left ventricle. J Am Soc Echocardiogr. 1989;2:408-14.

30. Ormiston JA, Shah PM, Tei C, Wong M. Size and motion of the mitral valve annulus in man: I. A two-dimensional echocardiographic method and findings in normal subjects. Circulation. 1981;64:113-20.

31. Vijayaraghavan G, Boltwood CM, Tei C, Wong M, Shah PM. Simplified echocardiographic measurement of the mitral annulus. Am Heart J. 1986;112:985-91.
32. Liel-Cohen N, Guerrero JL, Otsuji Y, et al. Design of a new surgical approach for ventricular remodeling to relieve ischemic mitral regurgitation: insights from 3-dimensional echocardiography. Circulation. 2000;101:2756-63.

33. Otsuji Y, Handshumacher MD, Liel-Cohen N, et al. Mechanism of ischemic mitral regurgitation with segmental left ventricular dysfunction: three-dimensional echocardiographic studies in models of acute and chronic progressive regurgitation. J Am Coll Cardiol. 2001;37: 641-8.

34. Helmcke F, Nanda NC, Hsiung MC, et al. Color Doppler assessment of mitral regurgitation with orthogonal planes. Circulation. 1987;75: 175-83.

35. Freed LA, Levy D, Levine RA, et al. Prevalence and clinical outcome of mitral-valve prolapse. N Engl J Med. 1999;341:1-7.

36. Box GEP, Cox DR. An analysis of transformations. $J$ R Stat Soc B. 1964;26:211-43.

37. Roberts R, Morris D, Pratt CM, Alexander RW. Pathophysiology, recognition, and treatment of acute myocardial infarction and its complications. In: Schlant RC, Alexander RW, editors. The heart: arteries and veins. New York: McGraw-Hill Inc; 1994. p. 1115.

38. Yiu SF, Enriquez-Sarano M, Tribouilloy C, Seward JB, Tajik AJ. Determinants of the degree of functional mitral regurgitation in patients with systolic left ventricular dysfunction: a quantitative clinical study. Circulation. 2000;102;1400-6.

39. Komeda M, Glasson JR, Bolger AF, et al. Mirror image of "compensatory mechanism" of papillary muscles with posterior or anterior LV wall ischemia. Circulation. 1996;94(Suppl I):I-442.

40. Bach DS, Bolling SF. Improvement following correction of secondary mitral regurgitation in end-stage cardiomyopathy with mitral annuloplasty. Am J Cardiol. 1996;78:966-9.

41. Bach DS, Bolling SF. Early improvement in congestive heart failure after correction of secondary mitral regurgitation in end-stage cardiomyopathy. Am Heart J. 1995;129:1165-70.

42. Rankin JS, Feneley MP, Hickey MS, et al. A clinical comparison of mitral valve repair versus valve replacement in ischemic mitral regurgitation. J Thorac Cardiovasc Surg. 1988;95:165-77.

43. Hung J, Otsuji Y, Handschumacher MD, Schwammenthal E, Levine RA. Mechanism of dynamic regurgitation orifice area variation in functional mitral regurgitation: physiologic insights from the proximal flow convergence technique. J Am Coll Cardiol. 1999;33:538-45.

44. Liel-Cohen N, Otsuji Y, Vlahakes GJ, Akins CW, Levine RA. Functional ischemic mitral regurgitation can persist despite ring annuloplasty: mechanistic insights. Circulation. 1997;96(Suppl I):I-540. 